\title{
GREEN TECHNOLOGY MEDIATED SYNTHESIS OF SILVER NANOPARTICLES FROM MOMORDICA CHARANTIA FRUIT EXTRACT AND ITS BACTERICIDAL ACTIVITY
}

\author{
JOSHI SC*, UTKARSH KAUSHIK, APROOVA UPADHYAYA, PRIYANKA SHARMA
}

Department of Zoology, Reproductive Toxicology Unit, Centre for Advanced Studies, University of Rajasthan, Jaipur, Rajasthan, India. Email: s_c_joshi2003@rediffmail.com

Received: 02 November 2016, Revised and Accepted: 07 December 2016

\section{ABSTRACT}

Objective: The synthesis of nanoparticles from biological processes is evolving a new era of research interests in nanotechnology. Silver nanoparticles are usually synthesized by chemicals and physical method, which are quite toxic and flammable in nature. This study deals with an environment friendly biosynthesis process of antibacterial silver nanoparticles using Momordica charantia fruit.

Methods: $\mathrm{AgNO}_{3}(5 \mathrm{mM})$ was allowed to react with fruit extract of $M$. charantia. Biosynthesis of AgNPs was optimized by changing temperature, $\mathrm{pH}$, and solvent. The silver nanoparticles so formed were characterized using ultraviolet-visible (UV-VIS) spectroscopy, Fourier transform infrared spectroscopy (FTIR), dynamic light scattering (DLS), atomic force microscope (AFM), and scanning electron microscopy (SEM).

Results: UV-VIS spectra show absorption peak between 420 and $430 \mathrm{~nm}$. The FTIR analysis showed the alcoholic, lactam, and nitro group present in the plant extract, which were responsible for the reduction in AgNPs. The SEM images showed the size distribution of the nanoparticles and the average size was found to be $50-100 \mathrm{~nm}$. By DLS analysis and AFM analysis, average sizes of the silver nanoparticles were of $150 \mathrm{~nm}$. The results of these analyses confirmed the formation of silver nanoparticles. Silver nanoparticles were tested against Bacillus cereus and Staphylococcus epidermidis strains using disc diffusion method and were found to be effective.

Conclusion: Silver nanoparticles so synthesized in this study using fruit extract of $M$. charantia are simple, easy, and effective technique of nanoparticles production.

Keywords: Silver nanoparticles, Momordica charantia, Optimization, Antibacterial, Atomic force microscope, Scanning electron microscopy.

(c) 2017 The Authors. Published by Innovare Academic Sciences Pvt Ltd. This is an open access article under the CC BY license (http://creativecommons. org/licenses/by/4. 0/) DOI: http://dx.doi.org/10.22159/ajpcr.2017.v10i3.16009

\section{INTRODUCTION}

Nanotechnology involves constructing and designing of matter at atomic level from bulk magnitude size depends on the comprehension, use and control of matter of bulk magnitude [1]. Nanoparticles range from 1 to $100 \mathrm{~nm}$ with unique physicochemical properties that make them different from those of the bulk particles [2]. Nanoparticles are extensively explored and investigated for antimicrobial [3]. One such metal nanoparticle with prominent antimicrobial activity is silver nanoparticles. Numbers of products, such as toothpaste, deodorants, bedding, washers, water purification systems, and shampoo, contain silver nanoparticles [2]. Silver nanoparticles can be synthesized by employing chemical and physical method $[4,5]$. Both the methods involve certain disadvantages such as toxicity, costly chemicals, require large space, and energy. Complete data are still lacking about exposure of these chemically or physically synthesized silver nanoparticles on environment and human being [6].

Deployment of biosynthetic technique applying plant extracts has established substantial forethought in recent times. Large scale production, easiness, economically feasible nature, and eco-friendliness equaled to the other prevailing approaches such as using fungi and bacteria which would not be possible with the physical and chemical ways for the production of metal nanoparticles.

In this study, the silver nanoparticles were synthesized from fruit extract of the plant Momordica charantia. The biosynthesized nanoparticles were characterized, optimized, and its antimicrobial activity against Bacillus cereus and Staphylococcus epidermidis was studied.

\section{METHODS}

The M. charantia fruits were collected from the market of Vaishali Nagar, Jaipur. Silver nitrate was purchased from Merck.

\section{Preparation from of fruit extract}

The fruit was washed thoroughly, wiped and chopped. The chopped fruit was then dried in oven. The dried chopped fruit was grounded well to make powder. $5 \mathrm{~g}$ of powder was weighed and dissolved in $50 \mathrm{ml}$ of distilled water. The solution was then boiled for 15 minutes at $50^{\circ} \mathrm{C}$. The solution was filtered, centrifuged at 9,000 rpm for 15 minutes and made up volume to $50 \mathrm{ml}$. The extract was stored in the refrigerator for further use.

\section{Biosynthesis of silver nanoparticles}

The biosynthesis of silver nanoparticles was done by adding $10 \mathrm{ml}$ of aqueous plant extract in $50 \mathrm{ml}$ of $\mathrm{AgNO}_{3}(5 \mathrm{mM})$ solution. The mixture was stirred on the magnetic stirrer for 45 minutes. The solution was then centrifuged 3 times at 9,000 rpm by washing the pallet each time by distilled water to remove the unbound ligands from the pallet. The final pallet is then dissolved in the distilled water and dried in the oven at $50^{\circ} \mathrm{C}$. The dried powder obtained was black in color.

\section{Characterization of nanoparticles}

The silver nanoparticles which were synthesized from fruit extract of M. charantia were characterized using U.V spectrophotometer, Fourier transform infrared spectroscopy (FTIR), dynamic light scattering (DLS), scanning electron microscopy (SEM), and atomic force microscope (AFM). 
After mixing plant extract and $\mathrm{AgNO}_{3}$ solution, ultraviolet-visible (UV-VIS) spectra (Visiscan 167) was carried out by scanning the solution in range of $300 \mathrm{~nm}$ to $800 \mathrm{~nm}$ where distil water was used as reference. Synthesized silver nanoparticles and plant powder both were mixed with $\mathrm{KBr}$ to determine functional group using FTIR spectroscopy (Shimadzu $8400 \mathrm{~S}$ ). The size distribution profiles of nanoparticles were analyzed using AFM (Nanosurf), DLS (Zetasizer and Malvern), and SEM (Zeiss).

\section{Antibacterial assay}

Staphylococcus epidermis (MTCC 26394) and B. cereus (MTCC 9017) are the pure strains purchased from IMTECH Chandigarh. Nutrient agar (Hi Media, India) and King's medium were used for the growth at $30^{\circ} \mathrm{C}$ and $28^{\circ} \mathrm{C}$ and subcultured before use. The antibacterial assay was done by disc diffusion method [7] by taking three types of the concentration of biosynthesized Ag NPs $25 \mu \mathrm{g} / \mathrm{ml}, 35 \mu \mathrm{g} / \mathrm{ml}$, and $45 \mu \mathrm{g} / \mathrm{ml}$.

\section{Optimization of biosynthesized silver nanoparticles}

Three parameters were selected and varied to optimize the biosynthesis of AgNPs are temperature, $\mathrm{pH}$, and solvent. The temperature of the $\mathrm{AgNO}_{3}(5 \mathrm{mM})$ solution was set at $10^{\circ} \mathrm{C}, 15^{\circ} \mathrm{C} 20^{\circ} \mathrm{C} 50^{\circ} \mathrm{C}, 60^{\circ} \mathrm{C}$, and $75^{\circ} \mathrm{C}$, in six different flasks, respectively. $10 \mathrm{ml}$ of plant extract was added in six different $\mathrm{AgNO} 3(5 \mathrm{mM})$ solutions, and the same procedure was followed as for the biosynthesis of Ag NPs. Another parameter for optimization involves the $\mathrm{pH}$ of the $\mathrm{AgNO}_{3}(5 \mathrm{mM})$ solution was set at $3,5,9$, and $11 \mathrm{pH}$ in four different flasks respectively. $10 \mathrm{ml}$ of plant extract was added to each $\mathrm{AgNO}_{3}(5 \mathrm{mM})$ solutions, and the same procedure was followed as for the biosynthesis of Ag NPs. Methanolic extract of fruit was prepared by using soxhlet apparatus. The $20 \mathrm{~g}$ fruit powder was dissolved in $300 \mathrm{ml}$ of methanol and extract was prepared in soxhlet apparatus for $36 \mathrm{hrs}$.

\section{RESULT AND DISCUSSION}

Nowadays, nanomaterials are at the most important platform of rapidly evolving nanotechnology phase. Nanomaterials are aiding contemporary technology to pact with nanosized matters, their irreplaceable properties specifically size dependent styles them greater materials and necessary in different human deeds. At present, nanomaterials are now being used in medical fields for example tissue engineering, strong antibacterial agent, detection for pathogens/proteins and drug carriers, etc., Size specificity and novelity have made silver nanoparticles popular in number of consumer products $[2,8,9]$. Biosynthesis of nanoparticles using plant material is becoming popular nowadays [10].

UV-VIS absorption spectrum was observed by Visiscan 167 UV-VIS spectrophotometer for bio reduction of silver ions to AgNPs mediated by $M$. charantia fruit extracts were observed by recording the absorption spectra, and show absorbance at between 420 and $430 \mathrm{~nm}$ (Fig. 1) which was due to excitation in surface plasmon vibration. This is the most important feature of metal nanoparticles, which is due to the



Fig. 1: Ultraviolet-visible spectra graph depicting reaction time of $\mathrm{AgNO}_{3}$ solution with Momordica charantia fruit extract electron oscillations that collectively gather around the surface of metal particles. In similar studies, it was found that the absorbance spectra showed the peak at 400-450 $\mathrm{nm}$ [11-13]

The silver nanoparticles formed by bioreduction process are stabilized by several capping ligands, which were characterized by FTIR analysis [14]. The FTIR measurements were carried out to identify the possible biomolecules responsible for the reduction of the silver ions into silver nanoparticles.

The peaks at $3650 \mathrm{~cm}^{-1}$ indicate the presence of $\mathrm{O}-\mathrm{H}$ stretching, the peaks at $3350-3300 \mathrm{~cm}^{-1}$ that of N-H stretching, $1650 \mathrm{~cm}^{-1}$ due to $\mathrm{C}=0$ stretching and the peak at $1513 \mathrm{~cm}^{-1}$ may be due to the presence of $\mathrm{N}-\mathrm{O}$ asymmetric nitro compounds in the plant extract (Fig. 2). Whereas in case of silver nanoparticles, the peaks at $3450 \mathrm{~cm}^{-1}$ indicate the presence of $\mathrm{O}-\mathrm{H}$ stretching, the peaks at $3350-3300 \mathrm{~cm}^{-1}$ that of $\mathrm{N}-\mathrm{H}$ stretching, $1650 \mathrm{~cm}^{-1}$ due to $\mathrm{C}=0$ stretching and the peak at $1550 \mathrm{~cm}^{-1}$ may be due to the presence of $\mathrm{N}-\mathrm{O}$ asymmetric nitro compounds in silver nanoparticle (Fig. 2). Anther study of FTIR spectrum analysis showed peaks between 1000 and $2000 \mathrm{~cm}^{-1}$ which confirmed the presence of proteins and other ligands required for the synthesis and stabilization of silver nanoparticles $[15,16]$.

Light scattering (Zetasizer, Malvern) technique was used to determine the size distribution profile of nanoparticles in suspension. The average mean size of silver nanoparticles comes out to $20-150 \mathrm{~nm}$ as shown in Fig. 3. This measurement depends on the size of the particle core, the size of surface structures, particle concentration, and the type of ions in the medium. When light hits small particles, the light scatters in all directions (Rayleigh scattering) as long as the particles are small compared to the wavelength (below $250 \mathrm{~nm}$ ). The other studies revealed that the average size of the silver nanoparticle synthesized from Pimenta dioica was 10-150 nm [17].

The silver nanoparticles extracted from $M$. charantia extracts were analyzed using AFM. Fig. 4 contains the micrographs obtained from the AFM measurements of the silver nanoparticles obtained using M. charantia extracts. Fig. 4 illustrates an AFM micrograph of biosynthesized silver nanoparticles scanned in an area of $50 \mu \mathrm{m} \times 49.5 \mu \mathrm{m}$. The figure contains the average lengths (measured along the longer axis of nanoparticles), widths (measured along the shorter axis of nanoparticles), and areas calculated for the biosynthesized silver nanoparticles. It is clear from the AFM micrograph that the average size of the biosynthesized Ag NPs was measured $150 \mathrm{~nm}$. The other results showed that the AFM analysis of silver nanoparticles synthesized from Acalypha indica leaf extract was of average size 100-200 nm [15].

SEM analysis shows high-density AgNPs synthesized by M. charantia fruit extract (Fig. 5). It was shown that relatively spherical and uniform AgNPs were formed with diameter of 76.6 to $136.6 \mathrm{~nm}$. The SEM image of silver nanoparticles was due to interactions of hydrogen bond and electrostatic interactions between the bioorganic capping molecules bound to the AgNPs. The nanoparticles were not in direct contact even within the aggregates (gold coating), indicating stabilization of the nanoparticles by a capping agent [15]. The SEM micrograph confirmed the synthesis of spherical silver nanoparticles in the size range of 60-180 $\mathrm{nm}$ in another study of biosynthesised $\mathrm{Ag}$ NPs from Carica papaya [15].

\section{Optimization of silver nanoparticles synthesis}

To determine the optimized conditions of synthesis of silver nanoparticles the temperature of the silver nitrate solution was varied (Fig. 6). The amount of silver nanoparticles synthesized at hot temperature was $44 \mathrm{mg}$ and at cold temperature was $122 \mathrm{mg}$.

$\mathrm{pH}$ induce the reactivity of extract with silver ions during biosynthesis of silver nanoparticles. Therefore, change in $\mathrm{pH}$ would bring significant change in yield. In this study influence of $\mathrm{pH}$ on nanoparticles yield was assessed under different $\mathrm{pH}$ condition of the reaction mixture of extract. The $\mathrm{pH}$ of silver nitrate solution was also varied to optimize 


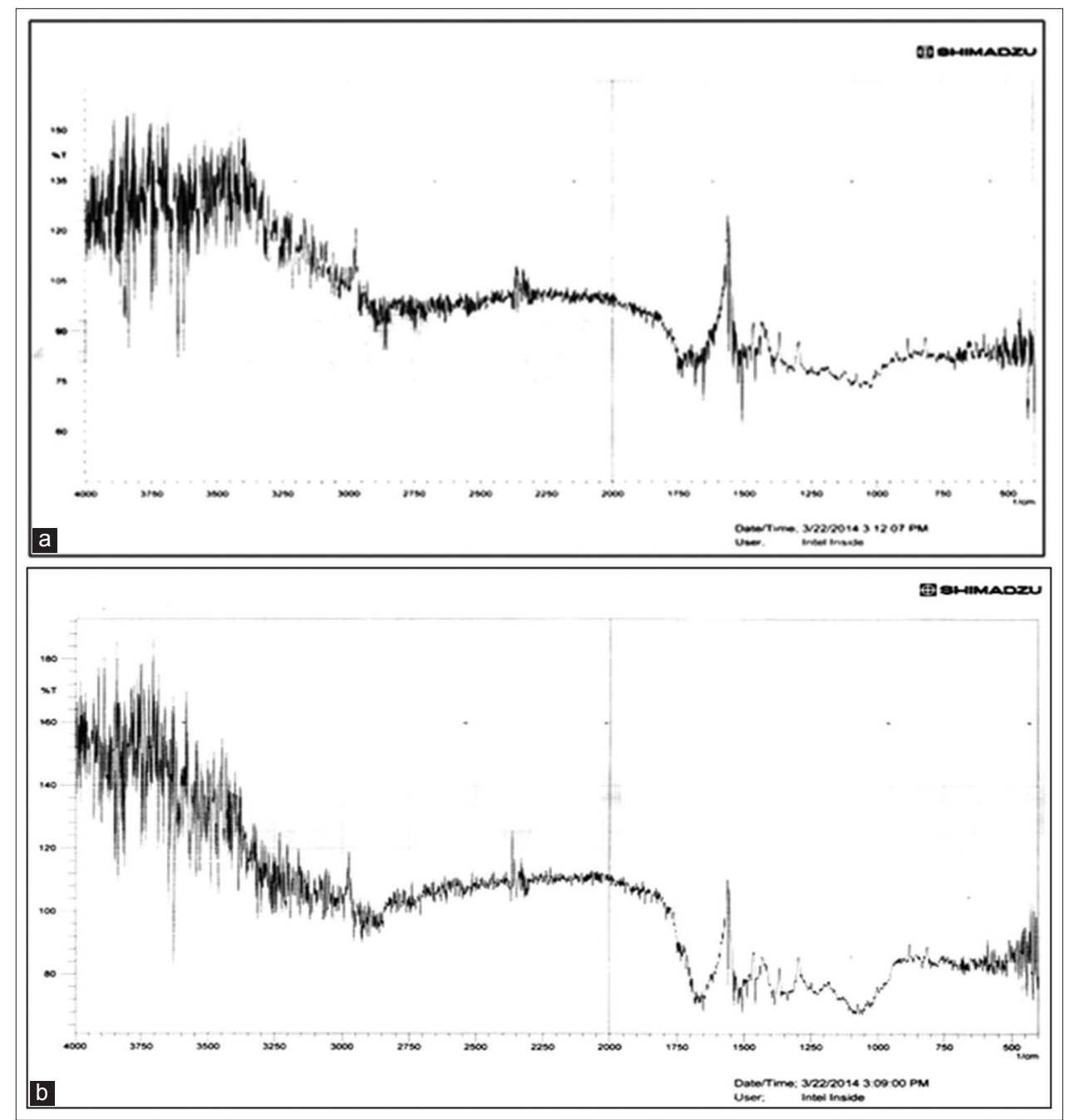

Fig. 2: Fourier transform infra-red spectroscopy image, (a) plant powder, and (b) biosynthesized silver nanoparticles

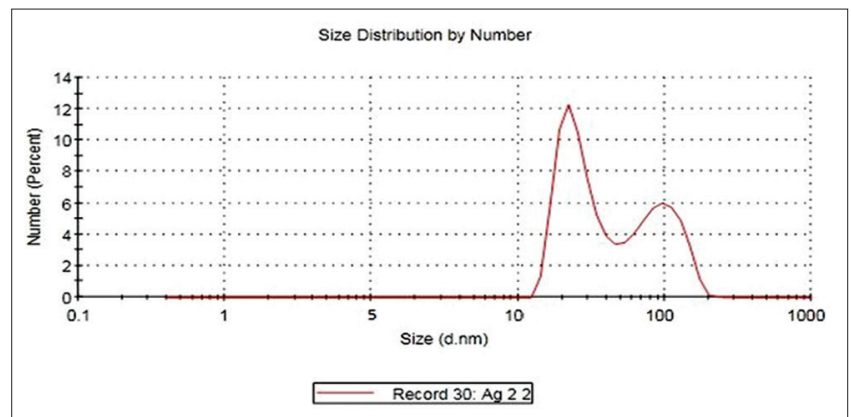

Fig. 3: Dynamic light scattering showing mean average size of biosynthesized silver nanoparticles

the synthesis of silver nanoparticles (Fig. 7). The amount of silver nanoparticles synthesized in acidic $\mathrm{pH}$ was $16 \mathrm{mg}$ and in the basic medium is $42 \mathrm{mg}$.

The synthesis of silver nanoparticle from fruit extract was optimized by changing the solvent of the fruit extract from aqueous to methanol. The amount of silver nanoparticles synthesized in methanolic solvent was $54 \mathrm{mg}$ (Fig. 8).

Silver is said to be a common antimicrobial substance for eras. Silver ions or salts have narrow effectiveness as an antimicrobial agent due to the interfering effect of salts and antimicrobial mechanism of continuous release of enough concentration of Ag ions from the metal form. This kind of limitation can be overcome by using silver nanoparticles. However, to use silver against microorganisms, it is essential to prepare it with cost-effective and environment-friendly methods.

The antibacterial effects of the bioreduced silver nanoparticles from $M$. charantia were investigated against two bacterial strains, B. cereus/MTCC-9017 (Gram-positive) and S. epidermidis/MTCC-2639 (Gram-positive) using the disc diffusion method.

The biosynthesized AgNPs were found to be effective at $45 \mu \mathrm{g} /$ $\mathrm{ml}$ against $S$. epidermidis and B. cereus, respectively, whereas at concentration of $35 \mu \mathrm{g} / \mathrm{ml}$ of silver nanoparticles shows intermediate effectiveness and at $25 \mu \mathrm{g} / \mathrm{ml}$ AgNPs were found to insensitive against both S. epidermidis and B. cereus. Table 1 and 2 shows the concentration of silver nanoparticles and diameters of the inhibition zones against S. epidermidis and B. cereus. Thus, silver nanoparticles synthesized using fruit extract of $M$. charantia have potential antibacterial activity against S. epidermidis and B. cereus (Fig. 9).

\section{CONCLUSION}

In this study, a simple methodology was endeavored to achieve a green eco-friendly approach for the synthesis of silver nanoparticles using $M$. charantia fruit extracts. The silver ions in an aqueous solution reacted with the M. charantia fruit extracts, the biosynthesis of AgNPs were specified by the rapid color change of plant extracts. The usual benevolent AgNPs were confirmed further by using UV-VIS spectroscopy. Alcoholic, 


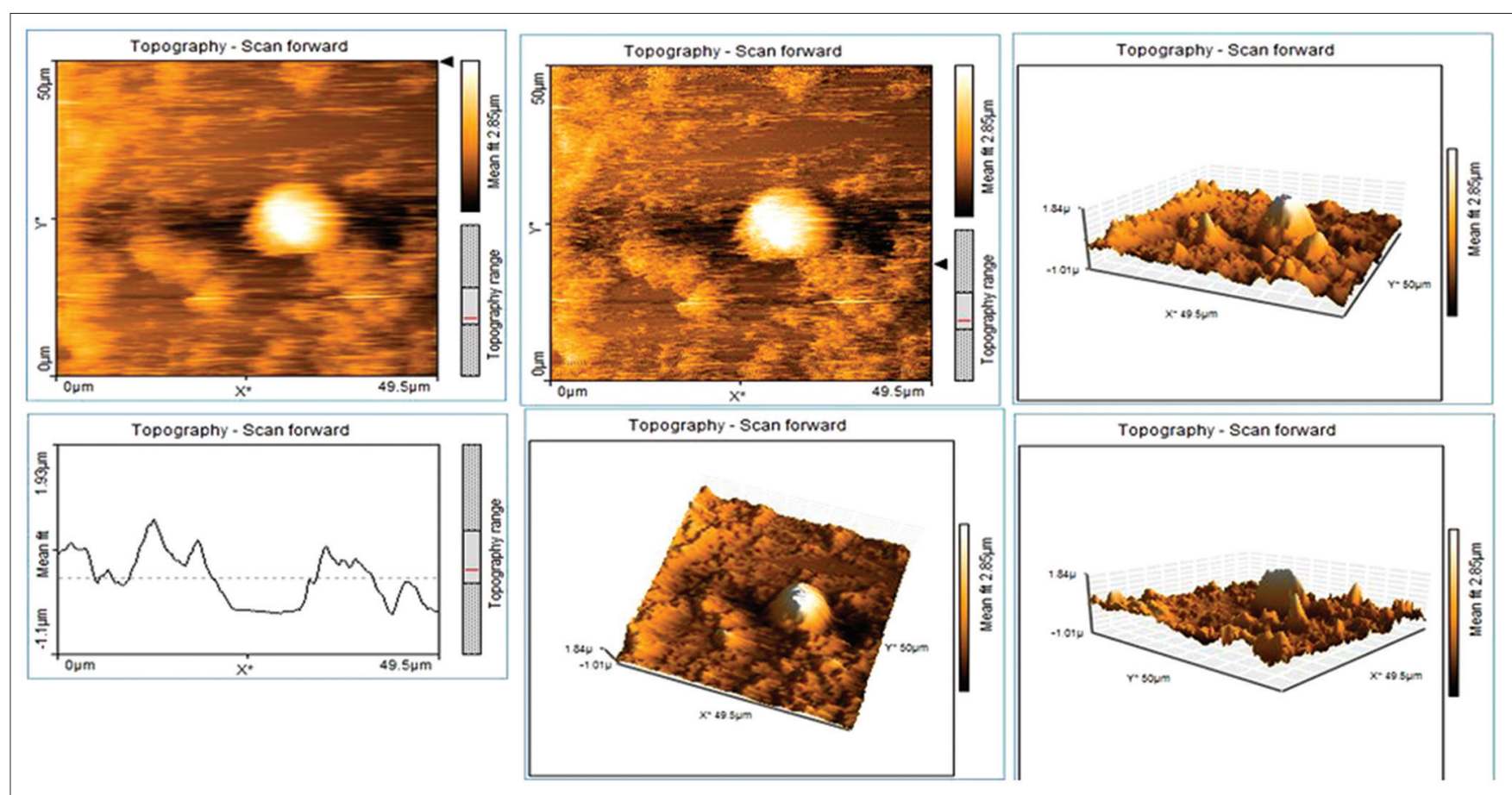

Fig. 4: Atomic force microscope micrograph of biosynthesized silver nanoparticles

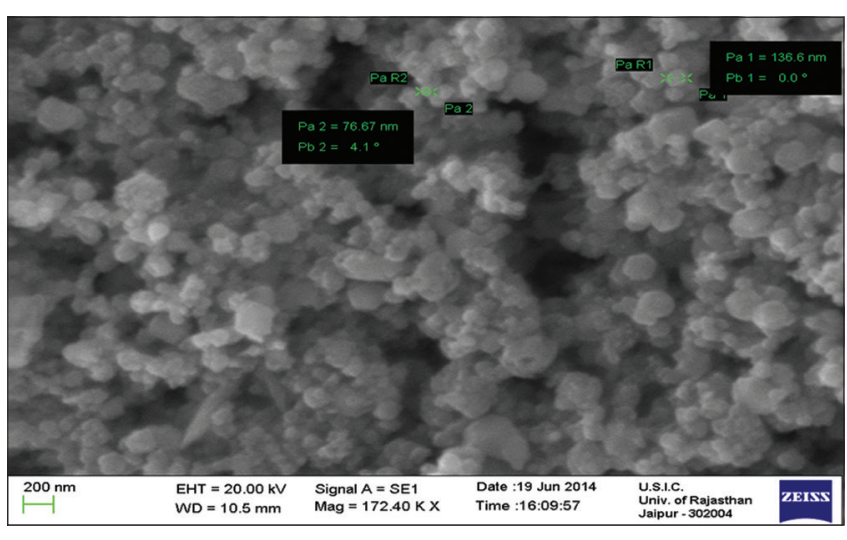

Fig. 5: Scanning electron microscopy micrograph of biosynthesized silver nanoparticles



Fig. 6: Histogram representation of amount of AgNPs synthesized by optimizing temperature

nitro and lactam groups were present in the fruit, and they serve as an effective reducing agent. AgNPs biosynthesized from $M$. charantia fruit extracts also exhibits great antibacterial activities against sample bacteria cultures. These biosynthesis silver nanoparticles

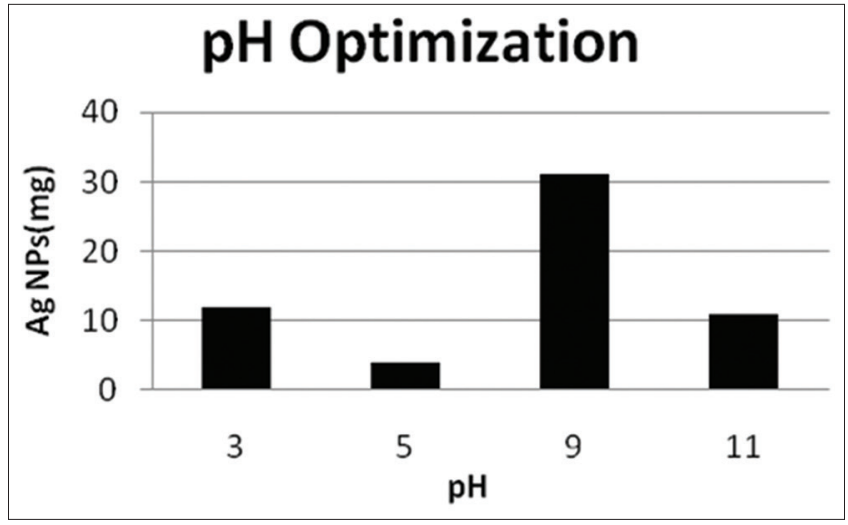

Fig. 7: Histogram representation of amount of AgNPs synthesized by optimizing $\mathrm{pH}$

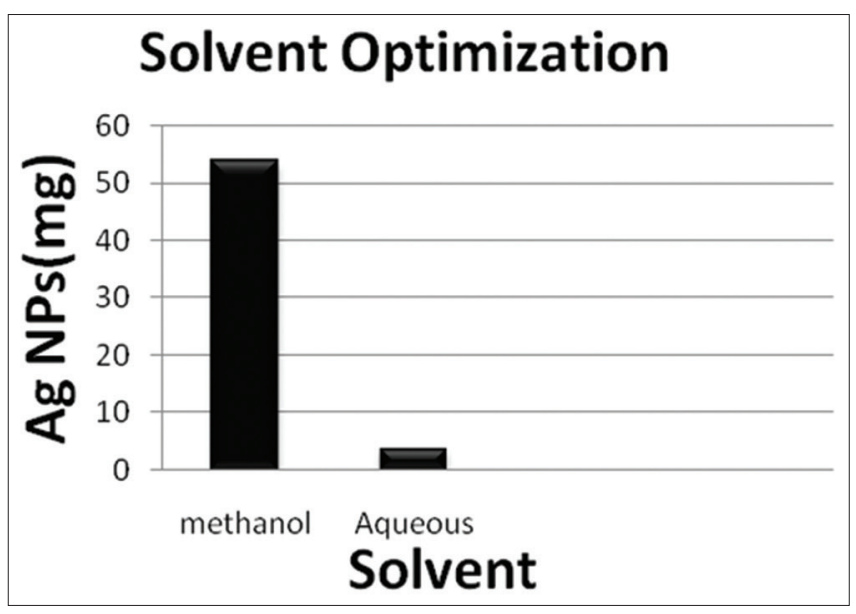

Fig. 8: Histogram representation of amount of AgNPs synthesized by optimizing solvent

can potentially be used for different medical applications. The cold temperature of the aqueous solution of $5 \mathrm{mM}$ of $\mathrm{AgNO}_{3}$, alkaline $\mathrm{pH}$ and 


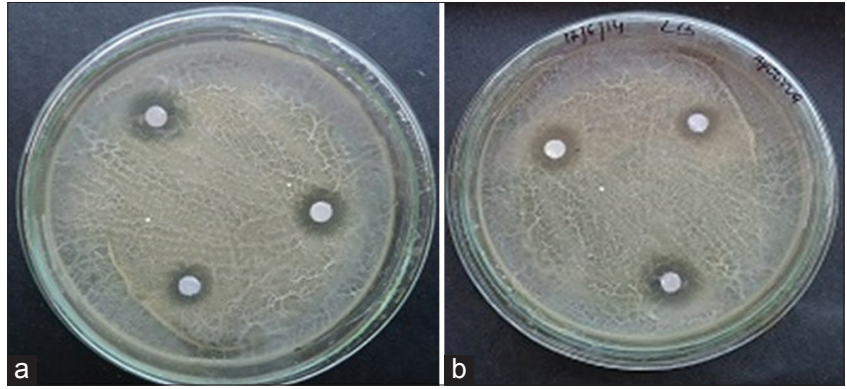

Fig. 9: Bacterial growth inhibition against bacterial strains.

(a) Staphylococcus epidermidis, and (b) Bacillus cereus

Table 1: Result showing measurement of zone of inhibition formed by AgNPs against $S$. epidermidis

\begin{tabular}{lll}
\hline Disk potency $(\boldsymbol{\mu g} / \mathbf{m l})$ & Zone of inhibition $(\mathbf{m m})$ & Inference \\
\hline 25 & 11 & Resistant \\
35 & 13 & Intermediate \\
45 & 16 & Sensitive \\
\hline
\end{tabular}

S. epidermidis: Staphylococcus epidermidis

Table 2: Result showing measurement of zone of inhibition formed by AgNPs against $B$. cereus

\begin{tabular}{lll}
\hline Disk potency $(\boldsymbol{\mu g} / \mathbf{m l})$ & Zone of inhibition $\mathbf{( m m})$ & Inference \\
\hline 25 & 12 & Resistant \\
35 & 13 & Intermediate \\
45 & 18 & Sensitive \\
\hline B. cereus: Bacillus cereus & &
\end{tabular}

B. cereus: Bacillus cereus

methanolic extract was proved as the best condition for biosynthesis of AgNPs from M. charantia fruit extracts.

\section{REFERENCES}

1. Feynman RP. There's plenty of room at the bottom. Science 1991;254(5036):1300-1.

2. Joshi SC, Kaushik U. Nanoparticles and reproductive toxicity: An overview. Res J Pharm Biol Chem Sci 2013;4(2):1396-410.
3. Ravishankar RV, Bai AJ. Nanoparticles and their potential application as antimicrobials. Science against microbial pathogens: Communicating current research and technological advances. In: Méndez-Vilas A, editor. Formatex Microbiology Series No. 3. VOL. 1. Spain: Formatex; 2011.

4. Senapati S. Biosynthesis and immobilization of nanoparticles and their applications. India: University of Pune; 2005.

5. Klaus-Joerger T, Joerger R, Olsson E, Granqvist C. Bacteria as workers in the living factory: Metal-accumulating bacteria and their potential for materials science. Trends Biotechnol 2001;19(1):15-20.

6. Kaushik U, Joshi SC. Effects of silver nanoparticles on liver functions of male albino rat. Int J Curr Res 2016;8(7):34748-52.

7. Bauer AW, Kirby WM, Sherris JC, Turck M. Antibiotic susceptibility testing by standardized single disc method. Am J Clin Pathol 1996;45(4):493-6.

8. Kaushik U, Joshi SC. Assessment of size based oral toxicity of silver nanoparticles on serum lipid profile, liver and kidney function of male Wistar rats. World J Pharm Res 2016;5(10):786-803.

9. Kaushik U, Joshi SC. Silver nanoparticles: Green synthesis, optical properties, antimicrobial activity and its mechanism using Citrus sinesis. Asian J Pharm Clin Res 2015;8(6):179-84.

10. Krishnaraj C, Jagan EG, Rajasekar S, Selvakumar P, Kalaichelvan PT, Mohan N. Synthesis of silver nanoparticles using Acalypha indica leaf extracts and its antibacterial activity against water borne pathogens. Colloids Surf B Biointerfaces 2010;76(1):50-6.

11. Ahmad N, Sharma S, Singh VN, Shamsi SF, Fatma A, Mehta BR. Biosynthesis of Silver Nanoparticles from Desmodium triflorum: A novel approach towards weed utilization. Biotechnol Res Int 2011;2011:454090.

12. Ahmad N, Sharma S. Green synthesis of silver nanoparticles using extracts of12. Ananas comosus. Green Sustain Chem 2012;2(4):141-7.

13. Ravindra BK, Rajasab AH. A comparative study on biosynthesis of silver nanoparticles using four different fungal species. Int J Pharm Pharm Sci 2014;6(1):372-6.

14. Selvi KV, Sivakumr T. Isolation and characterization of silver nanoparticles from from Fusarim oxysprum. Int J Curr Micobiol Appl Sci 2012;1(1):56-62.

15. Mude N, Ingle A, Gade A, Rai M. Synthesis of silver nanoparticles using callus extract of Carica papaya - A first report. J Plant Biochem Biotechnol 2008;18(1):83-6.

16. Bobbu P, Netala VR, Aishwarya S, Reddy IR, Kotakadi SV, Tartte V. Rapid synthesis of silver nanoparticles using aqueous leaf extract of Achyranthes aspera and study of their antimicrobial and free radical scavenging activities Int J Pharm Pharm Sci 2016;8(5):341-6.

17. Geethalakshmi R, Sarada D. Synthesis of plant-mediated silver nanoparticles using Trianthema decandra extract and evaluation of their anti-microbial activities. Int J Eng Sci Technol 2010;2(5):970-5. 